\title{
Global Business Cultures
}

\author{
Mrs. Aruna Deshpande \\ Associate Professor University of Mumbai ADMI
}

\begin{abstract}
Globalisation has made the availability of international products and services which can be accessed by individuals in many countries, from diverse economic backgrounds. Thus business culture reflected in organizations the extent to which society accepts that power is distributed unequally in institutions and organizations, likes formal rules; absolute truths masculine is assertive, acquisitive, values money and things and not caring for others, quality of life or people; whereas, femininity is nurturing and valuing quality of life, individual takes care of self and family and is low on organizational loyalty; collectivism is in-group or clan responsibility loyalty is owed to the group.

In cultures where people are emphasized, it is the quality of interpersonal relationships which is important. In cultures where ideologies are emphasized, sharing common beliefs is more important than group membership. In cultures where action is emphasized, what is done is more important than what is said. Styles of creating persuasive impressions for a long term sustainable business relations, and economically gaining.
\end{abstract}

Key words: Globalisation, Cultures, trust, beliefs, values.

\section{Introduction:}

Are you interested in different cultures? Do you like talking to different people and understanding why they do things differently? And what about in business? What is your experience of working with people from different countries? These questions can all lead to some very interesting discussions. But they are usually not very business focused. In international business you also need to understand how culture impacts all of the different aspects of your business.

The concept of culture can be devoted to all the richness of art, lifestyle, language, values and folklore of a nation or ethnic group. In the same way culture in organisations can be regarded as a unique blend of human values, attitudes and behaviour - its own culture.

Because of Globalisation, for the first time in history, the availability of international products and services can be accessed by individuals in many countries, from diverse economic backgrounds.

Hence more and more firms around the world are going Global including:

- Manufacturing firms

- $\quad$ Service companies (i.e. IT, Banks, Insurance, Tourism, etc.)

- Art, Film and Music companies.

\section{International Culture}

Understanding the culture in a country or region in which you are doing business is a critical skill for the international business person. Without this knowledge, a successful outcome to the business venture can be in jeopardy. Cross-cultural differences impact all interactions. This study is are going to look at how they impact the organization within a business. A good understanding of how culture impacts international business helps to manage risk better, identify the right business opportunities to seize, and generally provides with a framework to make international business a success and gives insights into how culture impacts international business.

Multinational

A multinational company is defined as an organization that has business activities in multiple countries. Local employees typically manage each country's organizations as separate entities with a corporate headquarters coordinating the strategy, resources and technology among the various businesses.

Global

A global company is one that is defined as an organization with operations around the world, whose strategies, resources and technology are shared and leveraged globally, regardless of national or geographic boundaries.

\section{International Environment:}

International environment is the process of national and sociocultural variables employing, developing and rewarding people in international or global organizations. It involves the worldwide management of people, not just the management of expatriates. An international firm is one in which operations take place in subsidiaries overseas, which rely on the business expertise or manufacturing capacity of the parent company. International firms may be highly centralized with tight controls. A multinational firm is one in which a number 
of businesses in different countries are managed as a whole from the centre. The degree of autonomy they have will vary.

Global firms offer products or services that are rationalized and standardized to enable production or provision to be carried out locally in a cost-efficient way. Their subsidiaries are not subject to rigid control except over the quality and presentation of the product or service. They rely on the technical know-how of the parent company, but carry out their own manufacturing, service delivery or distribution activities.

\section{Country Profile}

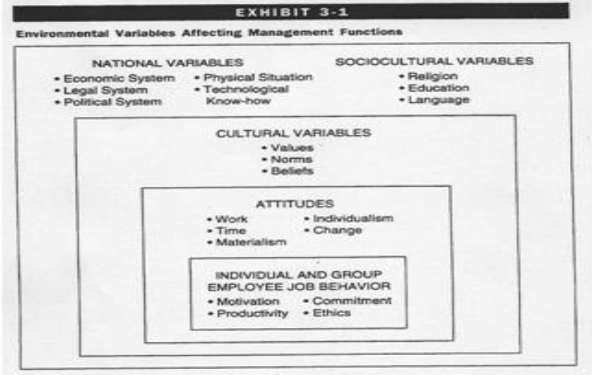

IV. Think Globally And Act Locally

The cultural differences mentioned above have produced the slogan 'think globally and act locally'. This means that an international balancing act is required, which leads to the fundamental assumption made by Bartlett and Ghoshal (1991) that: 'Balancing the needs of co-ordination, control and autonomy and maintaining the appropriate balance are critical to the success of the multinational company.'

Ulrich (1998) suggests that to achieve this balancing act, there are six capabilities that enable firms to integrate and concentrate international activities and also separate and adopt local activities:

1. being able to determine core activities and non-core activities;

2. Achieving consistency while allowing flexibility;

3. Building global brand equity while honouring local customs;

4. Obtaining leverage (bigger is better) while achieving focus (smaller is better);

5. Sharing learning and creating new knowledge;

6. Engendering a global perspective while ensuring local accountability.

Expatriates (nationals of the parent company or third-country nationals) may be required to provide the experience and expertise that local nationals lack, at least for the time being. But there is much to be said for a long-term resourcing policy that states that the aim is to fill all or the great majority of posts with local people. Parent companies who staff their overseas subsidiaries with local nationals always have the scope to 'parachute in' specialist staff to deal with particular issues such as the start-up of a new product or service.

\section{Literature Review:}

Globalization refers to a 'growing economic interdependence among countries, as reflected in the increased cross-border flow of three types of entities: goods and services, capital, and knowhow' (Govindarajan and Gupta, 2001, 4). Few spoke of 'world economy' 25 years ago, and the prevalent term was 'international trade' (Drucker, 1995). However today, international trade has culminated in the emergence of a global economy, consisting of flows of information, technology, money, and people, and is conducted via government international organizations such as the North American Free Trade Agreement (NAFTA) and the European Community; global organizations such as the International Organization for Standardization (ISO); multinational companies (MNCs); and cross-border alliances in the form of joint ventures, international mergers, and acquisitions. These inter-relationships have enhanced participation in the world economy, and have become a key to domestic economic growth and prosperity (Drucker, 1995, 153).

Laurent (1986) commented that: In order to build, maintain and develop the corporate identity, multinational organizations need to strive for consistency in their ways of managing people on a worldwide basis. Yet, and in order to be effective locally, they also need to adapt those ways to the specific cultural requirements of different societies. While the global nature of business may call for increased consistency, the variety of cultural environments may be calling for differentiation.

Perkins and Hendry (1999) argue that notwithstanding this fourfold model, international firms seem to be polarizing around two organizational approaches: 1) regionalization, where local customer service is important; and 2) global business streams, which involve setting up centrally controlled business segments that deal with a related range of products worldwide. 
The global human resource manager is encouraged to promote a spirit of multicultural interpersonal and inter organizational trust, within which members of the networked organizations can learn to cooperate (Barney \& Hansen 1994).

Hofstede (1980) points out, it follows that managers in one country behave in a way that is noticeably different from managers in other countries. Brewster (2004) concludes on the basis of his research that there is some convergence in Europe in the general direction of developments (directional convergence) such as the decreasing size of the HR function, increases in training and development and the increasing provision of information about strategy and finances. In cultures where people are emphasized, it is the quality of interpersonal relationships which is important. In cultures where ideologies are emphasized, sharing common beliefs is more important than group membership. In cultures where action is emphasized, what is done is more important than what is said. Hofstede (1980) emphasizes that there are a number of cultural dimensions that affect international operations. His framework has been adapted by Bento and Ferreira (1992) to produce the following cultural dualities:

- Equality versus inequality;

- Certainty versus uncertainty;

- Controllability versus uncontrollability;

- Individualism versus collectivism;

- Materialistic versus personalization.

Sparrow and Hiltrop (1997) note the following HR areas that may be affected by national culture:

- Decisions on what makes an effective manager;

- giving face-to-face feedback;

- Readiness to accept international assignments;

- Pay systems and different concepts of social justice;

- Approaches to organizational structuring and strategic dynamics.

The Perkins (1997) points out, it is necessary for businesses to 'remain competitive with their employment offering in the market place, to attract and retain high quality staff with worldwide capabilities'.

Policies are required on the employment of local nationals and the use of expatriates for long periods or shorter assignments. The advantages of employing local nationals are that they:

- are familiar with local markets, the local communities, the cultural setting and the local economy;

- speak the local language and are culturally assimilated;

- can take a long-term view and contribute for a long period (as distinct from expatriates who are likely to take a short-term perspective);

- do not take the patronizing (neo-colonial) attitude that expatriates sometimes adopt.

\section{Objective of the Study:}

- To understand the importance of Global Business Culture.

- To understand the traits to be considered while dealing with different people from different countries

- To appreciate the opportunities and challenges offered in different global cultures.

- Need to increase cross cultural awareness.

\section{Research Methodology:}

The research is focused on the studies of global business practices commonly used by countries across the world. The sociocultural styles used by the countries according to the values, beliefs, norms, behavioural patterns, religious beliefs used to do business along cross borders.

The paper is article based through secondary data and the empirical study done in the research conducted, correlated to the business expectations globally. The study focuses around the cultural beliefs for internet, research articles from CLC, books and journals online.

\section{Findings:}

International studies involve a number of issues not present when the activities of the firm are confined to one country. These issues comprise the variety of international organizational models that exist, the extent to which policy and practice should vary in different countries (convergence or divergence), the problems of managing in different cultures and environments, and the approaches used to select, deploy, develop and reward expatriates who could be nationals of the parent company or 'third-country nationals' (TCNs) - nationals of countries other than the parent company who work abroad in subsidiaries of that company.

\section{How Culture Impacts an International Business}

Cross-cultural differences impact all interactions. This study is going to look at how they impact the organization within a business.

- Are There Differences? 
- What makes an international business different?

- Does an international business function differently from one that is not international?

- Are there international growing pains?

Apart from the legalities of operating an international company, it is hard to identify any tangible differences.

The differences centre around collective "soft" skills. This obviously stems from the nature of "international skills" and "cross-cultural skills".

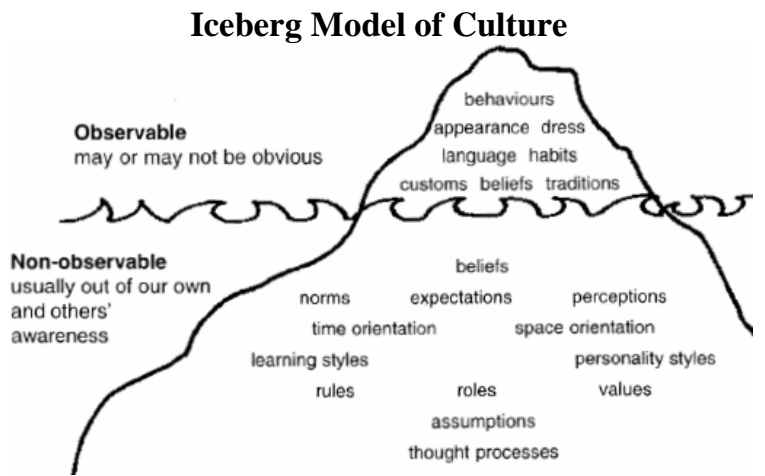

Culture is often compared to an iceberg which has both visible (on the surface) and invisible (below the surface) parts. Elements of culture which can be plainly seen, such as food or clothes, are represented by the upper portion of the iceberg. Those elements which are not as obvious such as why someone eats or dresses the way they do are represented by the much larger portion of the iceberg underwater.

Failure to understand and recognise these parts of culture and the layers that compose them, as well as how they influence each other is the main reason misunderstandings occur when doing business internationally.

Variations on the popular iceberg metaphor for culture explains the personal traits like personal preferences, languages, behaviour, practices, customs and norms followed, the sub-cultural traits that make sub-groups, and cultural backgrounds, which are deeply held beliefs and accepted norms.

\section{Cultural Influences}

There are some obvious ways culture influences an international business:

- The way how we present ourselves

- How we express opinions

- Assumptions based on the environment and context

- Perceptions of voice, and other personal physical details

- When you work inside an international company, you learn to adapt to these cultural differences.

- They stop interfering with communication.

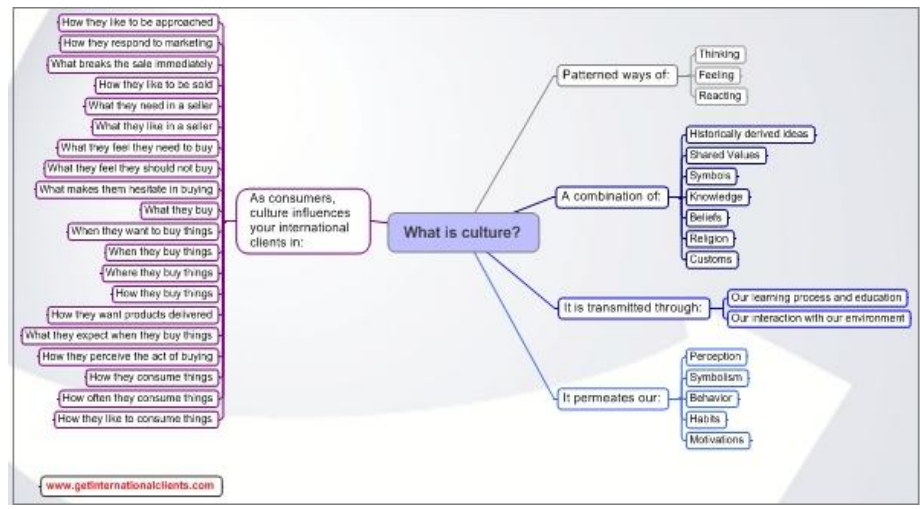

Hofstede's view of national culture reflected in organizations

- Power Distance - extent to which society accepts that power is distributed unequally in institutions and organizations

- Uncertainty Avoidance-likes formal rules; absolute truths

- Masculinity/Femininity - masculine is assertive, acquisitive, values money and things and not caring for others, quality of life or people; whereas, femininity is nurturing and valuing quality of life

- Individualism/Collectivism-individual takes care of self and family and is low on organizational loyalty; collectivism is in-group or clan responsibility loyalty is "owed" to the group 


\section{Uncertainty Avoidance}

The manner in which people adapt to their external environment is associated with how they deal with uncertainty. Americans are more willing to take risks and can live with a relatively high level of uncertainty. Other cultures (Asian) become very uncomfortable with uncertainty and prefer predictability and control. They work to avoid risk by setting out specific rules and maintaining the status quo. The lower the uncertainty avoidance, the more important success is, the greater the uncertainty avoidance, the more important security is.

High uncertainty avoidance is characterized by avoidance of uncertain and ambiguous situations. Tactics utilized to reduce the threat posed by such situations include the provision of greater career stability, the establishment of more formal rules, intolerance of deviant ideas and behaviors, belief in absolute truths and the attainment of expertise. As the level of uncertainty avoidance increases within a society so does aggressiveness, and a strong inner urge to work. In Hofstede's study, countries which were assessed to exhibit the lowest uncertainty avoidance included Singapore and Denmark while those demonstrating the highest were Greece and Portugal.

\section{Individualism/Collectivism}

Another dimension discovered by Hofstede was that of individualism versus collectivism.

Nations that display highly individualistic attitudes are comprised of a greater number of citizens who believe that their responsibility for support extends only as far as their immediate family while the social framework is tighter in collective societies. People in the collective cultures discriminate in-groups (relatives, institutions and organizations) and out-groups. Responsibility for care and loyalty extend beyond the immediate family to include all members of the in-group. Countries that rank highest in collectivism include Venezuela and Columbia and those that rank highest in individualism are the USA and Australia.

The Chart shows the rankings of several countries based on Hofstede's work.

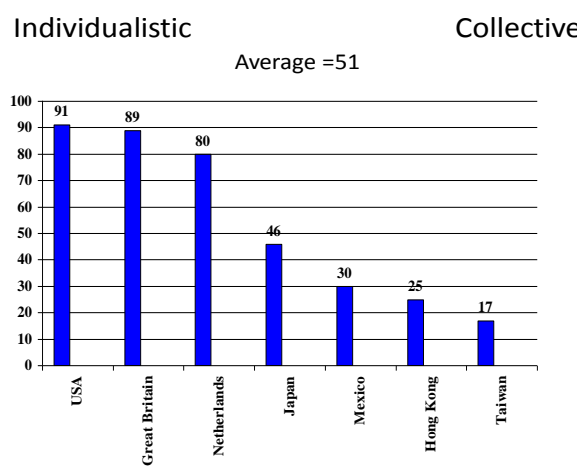

This chart demonstrates the relationships of some selected countries on the individualism/collectivism continuum.

In a collective society, an individual's identity is defined by the group - family or employer, social status where in an individualistic society one finds his identity within himself. The collective society relies on the group to make decisions where an individualistic society prefers individual decisions. The individualistic society prefers autonomy, variety, pleasure and individual security while the collective society focus more on what is good for the group.

It is the collective culture that believe that the nail that sticks up will get pounded down while individualistic societies reward personal achievements.

\section{Masculine/Feminine Dimensions:}

Masculine

- Material success

- Ambition, assertive

- Competitive

- Live to work

- Women are nurturers

- Achievement

Feminine

- Quality of life

- Relationships

- Concern for weak

- Work to live

- Men \& Women nurture

- Disapprove of high achievers 


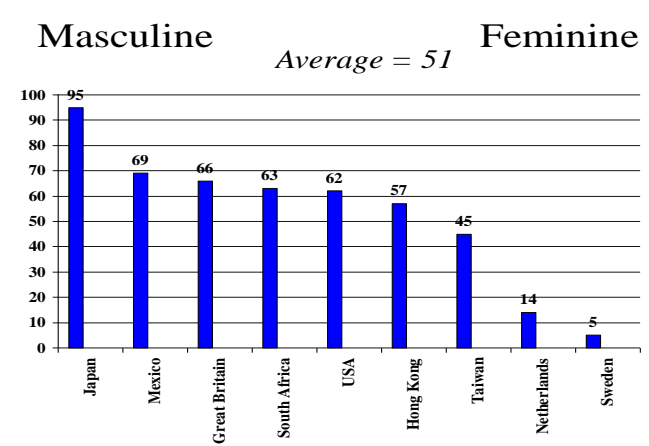

Those with a high score on the masculinity dimensions (above 51) feel that women should be the nurturers. They think the most important thing is one's ability to perform. They live to work and are ambitious. They admire achievers.

Those with lower scores feel that men as well as women should be nurturers and that the quality of life is more important than achievement or material success. They work to live. Service is their motivation. They also sympathize with unfortunates.

Where do you put yourself?

\section{Achievement and Ascription:}

Studies show that there is difference in the way people admired others. Those from achievement oriented cultures respect people based on what they have accomplished. People are admired and promoted for their actions and accomplishments.

On the other hand, cultures with an ascription orientation base respect on the position a person holds, the school they attended or the family from which a person came. For example, in France, a highly ascriptive culture, $90 \%$ of all CEO have graduated from a "grande ecole". Titles are used much more extensively in ascriptive cultures than in achievement oriented cultures. Ascriptive are more likely to promote people based on age and gender.

\section{Achievement:}

- Respected for what you do

- Respect of superior based on performance

- $\quad$ Limited use of titles

- Senior managers vary in age and gender, qualified by achievements

Aspirations:

- $\quad$ Respected for who you are

- Respect for superior seen as commitment to the organization

- Extensive use of titles Senior managers are male, middle-aged, qualified by background (who they are)

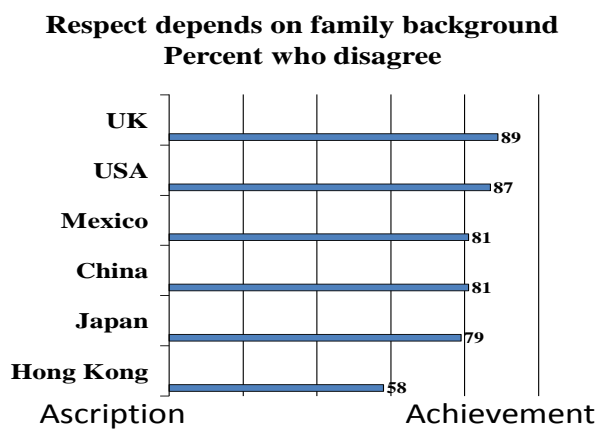

The survey asked people to agree or disagree with the statement that respect is dependent upon family background. As demonstrated in the slide nearly all Americans and British people disagreed with the statement. However, a relatively large number of people from Hong Kong (42\%) agreed that respect may not be based on achievement but instead on the family background of an individual.

Cultural impact on business in Canadian and Mexican countries on colleagues and customes:

Canadians work in:

- Control Environment,

- $\quad$ Single in time 
- Doing culture

- Low on contacts

- Direct and to the point

- Formal and work focused

- Individualism

Mexican work culture:

- Harmony mind set

- Multiple jobs at a time (Multitasking)

- Being is important

- High contacts

- Indirect communication and beat around the bush

- Informal style

- Believe in equality

\section{Cultural Conflict within A Company}

\section{Examples}

Some people may think that conflict within an international company is a result of the confrontation between cultures.

Although cultural personality issues and misunderstandings do happen, it is difficult to identify how culture influences teamwork within a company.

Most people learn to adapt to the different cultures and this enhances personal growth, interpersonal relations and intercultural interactions. international.

And this is where there may be differences in an international company and a company that is not

Most of the employees in an international company will be at a comparable level of personal growth. They will have similar interpersonal and intercultural skills.

And in a company that is not international, there could be wider differences in these areas.

\section{Case in Point: Breaking Growth Up into Manageable Projects at Company D}

In June 2003, rather than focusing on one area for growth, Company D enacted a growth strategy that involved several business areas. Company D created a six person team to divide the overall company growth initiative into discrete projects and align company culture with growth goals. The team consists of six employees: two from HR, a specialist from Operations, two additional specialists from other departments, and a consultant. Team membership will expand and contract on an as-needed basis and feature subcommittees revolving around specific aspects of the company's growth mandate (e.g. expanding market share in Africa). The team's five projects underscore the team's basic remit of moving from current practice to best practice and include:

1. Communications - communicating consistently and frequently to all parties

2. Diversity within the company culture - undertaking a cultural audit to ascertain if the company can expand with the people and competencies currently in place

3. Integration with its new business partner - examining if the company's integration with new business partners is running smoothly

4. Market expansion - identifying the firm's competencies and whether these will enable expansion into desired markets

5. Performance management culture - examining whether the performance management systems in place fully support the company's growth agenda

\section{Better Practices; Beyond soft skills...}

What is studied from working of international companies is that they seem to strive harder to implement standard and industry best practices.

- Best practices seem to lessen the clash of cultures within a company.

- These best practices are more widely accepted.

- They can also help to create a collective identity.

- Best practices can also lessen the clash of cultures outside the company when dealing with international clients. It does not matter where your clients are from, they also appreciate dealing with people that follow standard best practices.

- In the end it all comes down to working with good communication and within good business practices. 
The cultural synergies and differences while doing business with China has to be process oriented, proper hand shake, create a trusting relationships, by proper exchange of visiting cards, value to do right things with commitment, charisma, faith and guidance.

The gifts should not be wrapped in white as this colour is used for funeral, the gift should be packed in red colour as it is considered a colour of prosperity.

Main Ten spoken languages in countries:

- $\quad 1$ in 6 people speak Mandarin (1 billion)

- English: 380 million

- Spanish: 266 million

- Bengali: 189 million

- Hindi: 182 million

- Portuguese: 170

- Russian: 170

- Japanese: 125

- German 98

- Chinese (Wu): 77

Impact of global environment in current businesses

- Growth of China and India as manufacturing centres

- Concern over treatment of workers and the environment in less developed countries who may be suppliers

- The future direction of the interest rate, consumer spending, etc.

- The changing age structure of the population

- The popularity of 'fads' like the Atkins Diet

- The move towards greater political regulation of business

- The effect of more bureaucracy in the labour market

\section{Conclusions:}

When working in the global commercial environment, knowledge of the impact of cultural differences is one of the keys to international business success. Regardless of the sector in which you operate - finance, technology, or computers and consumer electronics - global cultural differences will directly impact on you and the profitability of your business.

The global cultural dimensions should focus on the below areas for business success:

- Power Distance - how should the boss act

- Uncertainty Avoidance - rules or common sense

- Masculine/Feminine - material rewards or quality of life

- Individualism/Collectivism - I versus we

- Universalistic/Particularistic - treat all equally versus do favors for friends

- Achievement/Ascription - respect for what you do or respect for who you are

- Locus of Control - I am in control of my destiny versus outside forces are in control

- Neutral/Affective - hide versus display emotions

- Diffuse/Specific (high/low context) - indirect versus direct communication

Improving levels of cultural awareness can help companies build international competencies and enable individuals to become more globally sensitive. The culture-focused country profiles contained in the World Business Culture website are your passport to international business expertise. If you don't have the right level of knowledge about these issues, you are taking a gamble every time you work cross-border - why bet on the future of you business or your career?

\section{Bibliography and Internet References}

[1]. PDF file obtained at www.arthuranderson.com

[2]. Jan, ucc.edu/... Role of Culture in International Management

[3]. www.bized.co.uk

[4]. You tube videos: on Cultures in China, Canadian and Mexican Cultural studies by Prof. Spies., Jeff Castle.

[5]. www.uk.sagepub.com

[6]. CLC; www.corporateleadershipcouncil.com, Building Organisation Culture for High Performance 2004. Managing relationships in China 2006 